\title{
Analysis of Conical Sealing and Spherical Sealing Structure
}

\author{
Wei $\mathrm{Li}^{1,2}$, Hong-Xiang Lei ${ }^{1,2}$ \\ ${ }^{1}$ Mechanical and Electrical Engineering, Southwest Petroleum University, Chengdu, Sichuan, China
}

${ }^{2}$ Key laboratory of oil and gas equipment the ministry of education, Southwest Petroleum University, Chengdu, Sichuan, China

\begin{abstract}
The article takes $60^{\circ}$ hydraulic fittings as the research object and uses the finite element analysis software ABAQUS to analyze cone sealing model and multi-group spherical sealing models with different arc radius, study cone sealing contact stress distribution and spherical sealing contact stress and sealing width, and analyze the Von Mises stress of the connecting thread. Analysis results show that: the contact stress peak of cone sealing appears on both ends of the sealing surface and it's sealing ability relies on intermediate section of sealing surface. The seal width of spherical sealing increases but the contact stress decreases with increasing of arc radius. When arc radius grows, peak stress is closer to the both ends of sealing surface and the contact stress distributes more uniformly.
\end{abstract}

Keyword: conical sealing; spherical seal ; contact stress ; sealing width; sealing performance

\section{Introduction}

Conical sealing and spherical sealing are a way of sealing, which's sealing pressure is originated from the action of the axial force. Because it's working surface is not liable to rolled up hard rubbish and it has more sealing pressure under the axial force, conical sealing and spherical sealing usually are applied on hydraulic fittings and valves which are suitable for work conditions with high temperature, high temperature pressure and minor diameter ${ }^{[1]}$. There are many factors to ensure sealing property, in which contact stress of sealing surface and sealing width have important effects on sealing property ${ }^{[2-4]}$. Based on the two factors, the author started studying sealing property of conical sealing and spherical sealing. ABAQUS is a powerful finite analysis software for engineering simulation. From linear analysis to many complex non-linear problem can be solved. A large number of complex nonlinear problems can be easily simulated by different combination. Applying ABAQUS finite element software and changing some design parameters, we can find optimum design scheme. It will help to reduce design period, the substantial human and materials ${ }^{[5]}$. In this paper, taking a certain type of hydraulic fittings model as an example, author applied ABAQUS software to analyze sealing property of conical sealing and spherical seal with different arc radius.

\section{Sealing Structure}

Author selected common $60^{\circ}$ hydraulic fittings as the research object to study conical sealing and spherical sealing that hydraulic fittings often adopt as a sealing method. Conical sealing and spherical seal have the same structure that mainly is consist of two parts: valve body and valve seat, as shown in Figure 1. Valve body and valve seat are connected through screw thread. Pre-tightening force produced by tighten screw thread will make sealing surface of vale body and sealing surface of vale seat fit closely together to seal. The sealing surface of conical sealing are two $60^{\circ}$ cones and its contact type is surface-to-surface, as shown in Figure 2-a. The sealing surface of spherical sealing vale body is cambered surface (radius $=\mathrm{R}$ ) and sealing surface of vale seat is two $60^{\circ}$ cone. The initial contact type of spherical seal is line-to-surface, as shown in Figure 2-b.

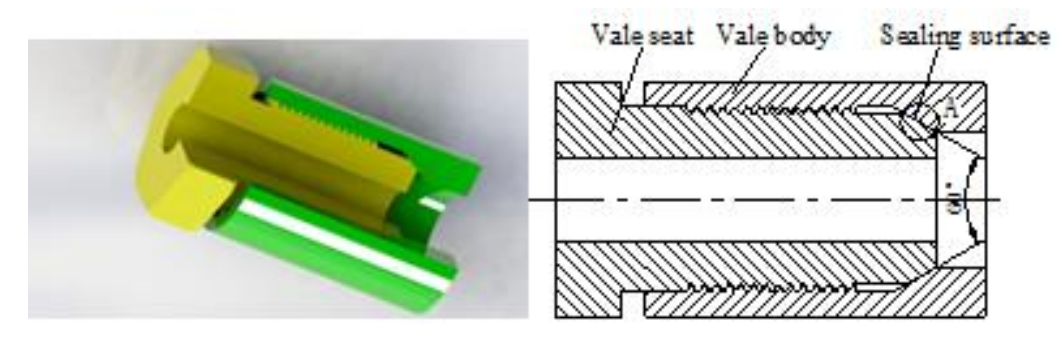

Figure 1: Sealing structure 


\section{International Journal of Science and Research (IJSR) \\ ISSN (Online): 2319-7064}

Index Copernicus Value (2013): 6.14 | Impact Factor (2015): 6.391

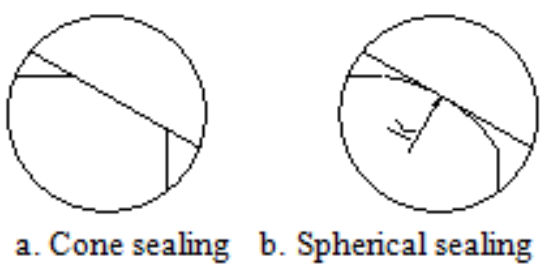

Figure 2: Enlarged view of A

\section{Models of Finite Element Simulation}

\subsection{Mathematical Model}

Because 3D model including lead angle would bring about extensive calculation in the finite element simulation, and sealing structure and loads are axisymmetric, the author neglected effect of lead angle and adopt 2D axisymmetric model to analyze sealing structure. Physical equations for axisymmetric problems are as follows:

$$
\left\{\begin{array}{c}
\sigma_{\varphi}=\frac{E}{1+\mu}\left(\frac{\mu}{1-2 \mu} \theta+\varepsilon_{\varphi}\right) \\
\sigma_{\rho}=\frac{E}{1+\mu}\left(\frac{\mu}{1-2 \mu} \theta+\varepsilon_{\rho}\right) \\
\sigma_{z}=\frac{E}{1+\mu}\left(\frac{\mu}{1-2 \mu} \theta+\varepsilon_{z}\right) \\
\tau_{x \varphi}=\frac{E}{2(1+\mu)} \gamma_{x \rho}
\end{array}\right.
$$

Where $\sigma_{\rho}, \sigma_{\varphi}$ and $\sigma_{z}$ are the normal stress components; $\tau_{z \varphi}$ is shear stress component, $\varepsilon_{\varphi}, \varepsilon_{\rho}, \varepsilon_{z}$ and $\gamma_{z \rho}$ are the strain components; $E$ is Young's elastic modulus and $\mu$ is Poisson's ratio. structure with different thread turns were established, subdivided modeling parameters as shown in table 1 .

Table 1: Parameter of building

\begin{tabular}{|l|r|r|r|r|r|l|l|}
\hline Modeling datum & \multicolumn{7}{|c|}{ Parameter } \\
\hline Arc radius /mm & 10 & 20 & $\ldots$ & 100 & 110 & $\infty$ (conical sealing) \\
Thread turns & 4 & 6 & $\ldots$ & 12 & 14 & 16 \\
\hline
\end{tabular}

\subsection{Define Contact}

The process of sealing includes state nonlinear (contact of sealing surface and thread) and material nonlinear (elastic-plastic deformation of sealing surface ${ }^{[6]}$. As same as elastic-plastic finite element problem, definite condition to nonlinear contact issue contains finite element equilibrium equations, boundary conditions, friction model, material constitutive model and contact constraints, etc. The contact constraints include 3 states which are separation, adhesion and sliding. Displacement of adhesion and sliding must meet the impermeable condition. The impermeable condition can be expressed as ${ }^{[7,8]}$

$$
n^{T} \Delta u-g \leq 0
$$

Where $\Delta u$ is relative displacement matrix of contact body, $\boldsymbol{n}$ is normal vector of sealing surface, and $\mathrm{g}$ is initial contact gaps.

The principle of minimum potential energy for elastic-plastic contact analysis is that the real solution makes total potential energy of the elastic system take minimum value:

Finite element models of conical sealing structure, spherical sealing structure with different arc radius and sealing

$$
\left.\Pi=\Pi\left(\varepsilon_{i j}, u_{i}, \lambda\right)=\int_{V} \frac{1}{2} D_{i j k l} \varepsilon_{i j} \varepsilon_{k l}-\bar{f}_{i} u_{i}\right) d_{V}-\int_{S} \bar{T}_{i} u_{i} d_{S}-\lambda^{T} C u
$$

Where $\bar{f}$ is body force, $\bar{T}_{i}$ is surface force of boundary, $\boldsymbol{C}$ is constraint matrix, $\lambda$ is lagrangian multiplier vector. Matrix form of formula 2 can be expressed as:

$$
\Pi(u, \lambda)=\frac{1}{2} u^{T} K u-u^{T} F-\lambda^{T} C u
$$

Where $\boldsymbol{u}$ is displacement matrix, $\boldsymbol{K}$ is stiffness matrix, $\boldsymbol{F}$ is load vector of node.

The interaction between the contacting surfaces contains two parts: the normal reaction between the contacting surfaces and the tangential reaction between the contacting surfaces ${ }^{[9]}$. It is very difficult to simulate real friction behavior, so the simulation analysis of ABAQUS uses a permissive elastic sliding friction formula. Male thread and sealing surface of valve body are defined as master surface. Female thread and sealing surface of valve seat are defined as slave surface. The friction coefficient between thread teeth is set to 0.12 . The friction coefficient between sealing surface is set to 0.05 .

\subsection{Applied load}

Because the simulation model is $2 \mathrm{D}$, left and right side of valve seat were imposed on fixed constraint, top surface and lower surface of valve body were imposed on displacement constraint to limit the displacement in y direction. The left side of valve body was applied load $260000 \mathrm{~N}$ in $\mathrm{x}$ direction to simulate thread pre-tightening force.

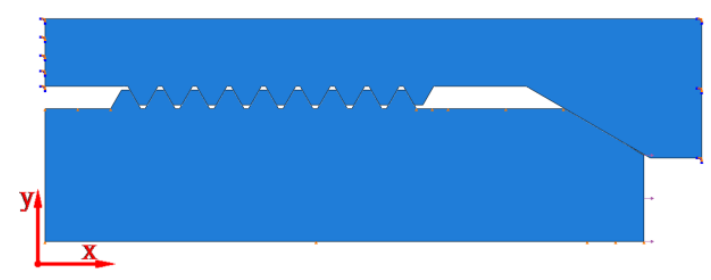

Figure 3: Applied load

\section{Volume 5 Issue 6, June 2016 www.ijsr.net}




\subsection{Mesh}

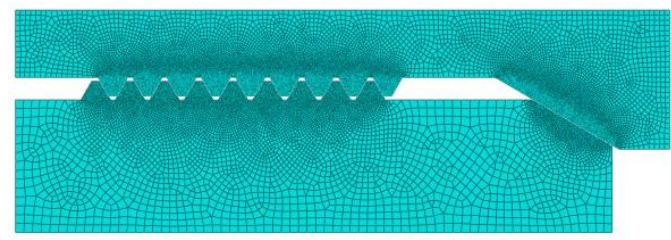

Figure 4: Mesh model

The grid division of the computational model is completed using the 8-node biquadratic axisymmetric quadrilateral (CAX8), and the implicit t integral is introduced to complete the calculation. CAX8 introduces enriched freedom degree of cell displacement gradient into linear element and can overcome shear locking problem that will happen in linear full-integration. In order to get a more accurate result, the grid of contact surface is densified. The local size of master surface's grid is set to $0.02 \mathrm{~mm}$ and the local size of slave surface's grid is set to $0.01 \mathrm{~mm}$.

\section{Results and Discussion}

The contact stress and sealing width reflect sealing performance. The higher contact stress and the wider sealing width is, the better seal performance is. Von Mises stress reflects difference value of principal stress. The excessive Von Von Mises stress will accelerate material yield and lead to surface fatigue cracks.

\subsection{Stress analysis of cone sealing}

Figure 5 is the Von Mises stress distribution of cone sealing structure in different parts. Figure 6 is the contact stress nephogram of sealing surface. Figure 7 is the contact stress distribution curves of sealing surface in direction of figure 6 arrow. As can be seen from Figure 7, the contact stress distribution curves of sealing surface looks U-shaped. Stress peak occurred on the both ends and the intermediate stress value is around $100 \mathrm{MPa}$. The maximum stress value of contact surface reaches $700 \mathrm{MPa}$. The minimum stress value only reaches $65 \mathrm{MPa}$. The average stress value is $135 \mathrm{MPa}$. The maximum value is about 11 times as much as the minimum value. Although the stress in the both ends is larger, the contact width is narrow. The stress in the middle of the sealing surface is smaller, but the contact width is wide. Conical sealing depend on intermediate section to seal.

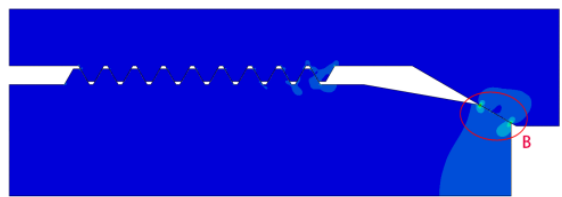

Figure 5: Miese Stress nephogram of cone sealing

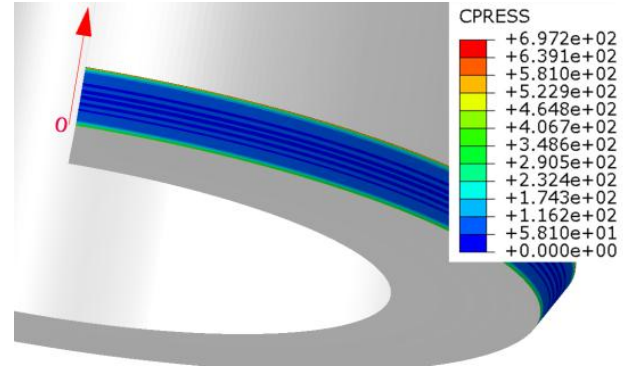

Figure 6: Contact stresses distribution of cone sealing

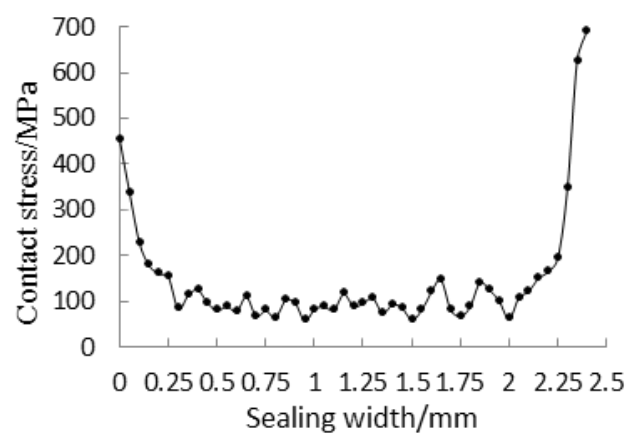

Figure 7: Stress distribution curves of sealing surface

\subsection{Stress analysis of spherical sealing}

Through the analysis of spherical sealing structure model with different arc radius, the stress distribution of sealing surface, the relation between sealing width and arc radius, the relation between the average contact stress and arc radius were obtained respectively.

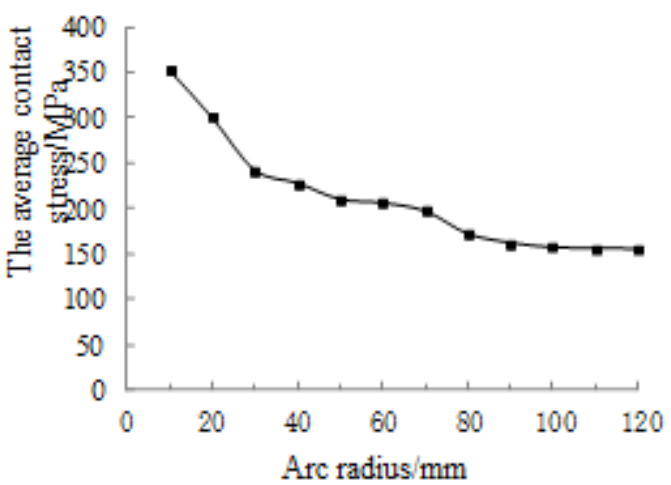

Figure 8: Average contact stress changing along with radius

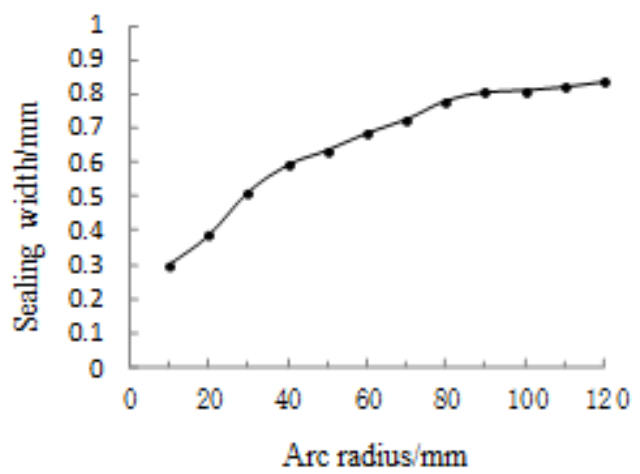

Figure 9: Sealing width changing along with radius

Figure 8 is effect of arc radius on the average contact stress

\section{Volume 5 Issue 6, June 2016 www.ijsr.net}




\section{International Journal of Science and Research (IJSR) \\ ISSN (Online): 2319-7064 \\ Index Copernicus Value (2013): 6.14 | Impact Factor (2015): 6.391}

Figure 9 is effect of arc radius on the sealing width. As can be seen from Figure 8 and 9, when radius grows, the average contact stress continuously decreases and the sealing width continuously increases. The decreasing amplitude of the average contact stress and the increasing amplitude of the sealing width continuously reduce.

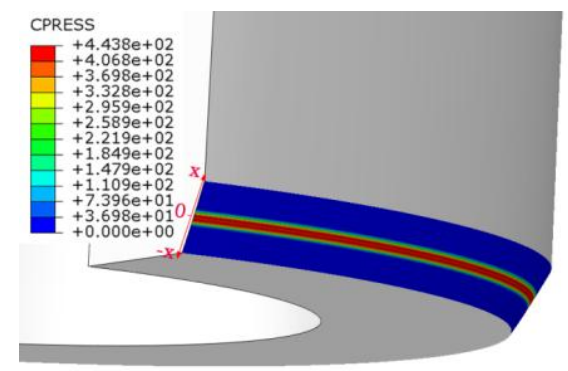

a. $\mathrm{R}=20 \mathrm{~mm}$

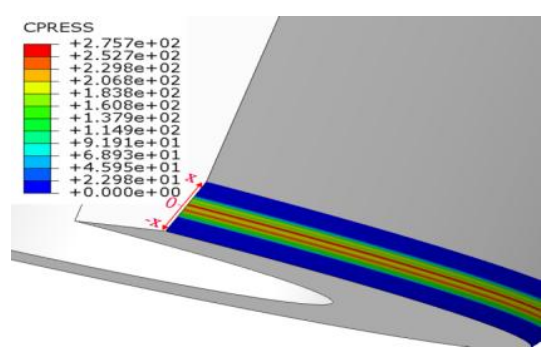

a. $\mathrm{R}=70 \mathrm{~mm}$

Figure 10: Contact stresses distribution of spherical seal

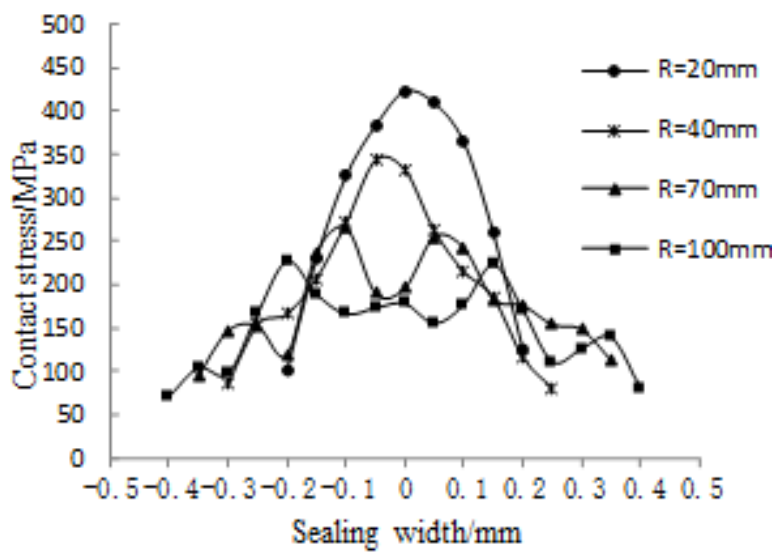

Figure 11: Stress distribution curves of different radius sealing surface

The paper analyzed contact stress distribution on the sealing surface of spherical sealing model with radius of $20 \mathrm{~mm}$, $40 \mathrm{~mm}, 70 \mathrm{~mm}$ and $100 \mathrm{~mm}$. Figure 10 is contact stress nephogram on the sealing surface of radius $20 \mathrm{~mm}$ and $70 \mathrm{~mm}$. Figure 11 is the contact stress distribution curves of sealing surface with different arc radius in direction of figure 10 arrow and tangency point as origin. As shown in Fig.11, the middle part of contact stress distribution curves of sealing surface with small radius is above the middle part of contact stress distribution curves of sealing surface with big radius. It suggests the smaller radius of sealing surface, the higher the contact stress of the middle part on contact surface.

When radius is smaller, the contact stress distribution is single peak curve and the maximal contact stress appears on the initial tangency point of sealing surface. Along the tangency point extend to the both ends, the contact stress decreased rapidly, such as the contact stress distribution curves with radius of $20 \mathrm{~mm}$ and $40 \mathrm{~mm}$. When the radius reaches a certain value, contact stress distribution is bimodal curve, the maximal contact stress doesn't appears on the initial tangency point of sealing surface but appears on the both sides of the initial tangency point,. such as the contact stress distribution curves with radius of $70 \mathrm{~mm}$ and $100 \mathrm{~mm}$.

Conical sealing is a special spherical sealing. The arc radius of conical sealing is infinite. As can be seen from the analysis results of the previous section, the stress peak of conical sealing occurred on the both ends of contact surface, which is consistent with the trend that spherical sealing peaks stress get closer to two ends with the increase of the radius. When radius is lesser, contact stress dropped fast and the distribution of contact stress is inhomogeneous. As radius increases, the fluctuation of contact stress cut down and the distribution of contact stress become more uniform.

\section{Conclusions}

1) The stress peak of cone sealing occurred on the both ends of sealing surface. There is a significant difference between the minimum stress and maximum stress. The sealing capacity of cone sealing depends on intermediate section of sealing surface where stress value is smaller but contact width is wide. Because of smaller stress on intermediate section, the sealing capacity of cone sealing is limited.

2) Spherical sealing contact stress reduces and sealing width increases with arc radius growing. When arc radius is smaller, the peak stress appears on tangency point of sealing surface .When arc radius grows, peak stress is closer to the both ends of sealing surface and the contact stress distribute more uniformly. During the spherical sealing structure design process, aiming at different working conditions, when selecting arc radius, both contact stress and sealing width should be considered to achieve the best sealing.

\section{References}

[1] Lun WP. Valve Design Entry and Master [M]. Beijing, China: China Machine Press, 2009. (in Chinese)

[2] PHILLIPS Dawnr R, WINGATA Robert J. Seal analysis for the ares -I upper stage fuel tank manhole covers [R] . USA: AIAA, 2010.

[3] Zhang BL. Reason of Valve Leakage and Optimization of its Choice $[\mathrm{J}]$. Environmental Protection in Petrochemical Industry, 2003, 26(2): 58-61. (in Chinese)

[4] Bu YH, Kong H, Guo AP, et al. Optimization Study on Primary Sealing of the Premium Connections[J]. Lubrication Engineering, 2011, 36(4): 15-20. (in Chinese)

[5]Zhang JW. ABAQUS 6.12 Finite Element Analysis [M]. Beijing: China Machine Press, 2014. (in Chinese)

\section{Volume 5 Issue 6, June 2016 www.ijsr.net}




\section{International Journal of Science and Research (IJSR) \\ ISSN (Online): 2319-7064}

Index Copernicus Value (2013): 6.14 | Impact Factor (2015): 6.391

[6] Han C, Zhang Y. Research on Sealing Property of Globe-Cone Joint for Pipeline [J] . Lubrication Engineering, 2012, 37 (10): 105-111.

[7] Zhou W, Le P, Chang XL, et al. Clough contact model based on the augmented Lagrangian multiplier and its application [J]. Rock and Soil Mechanics, 2008, 29(1):68-74. (in Chinese)

[8] SIMO JC, TAYLOR R L. Quasi incompressible finite elasticity in principal stretches: continuum basis and numerical algorithms[J]. Computational Methods in Applied Mechanics and Engineering, 1991, 85 : 273-310.

[9] Chen J, Hu J, Zhao YL. Impact Analysis of Friction on the Drawing Die Based on ABAQUS [J]. Machinery Design and Manufacture, 2013, 51 (6) 228-230. (in Chinese) 